\title{
Complete rupture of the long head of the biceps tendon and the distal biceps tendon
}

\author{
Author: \\ Pieter J. Oberholzer ${ }^{1}$ \\ Affiliation: \\ ${ }^{1}$ Department of Radiology, \\ University of Pretoria, \\ South Africa \\ Correspondence to: \\ Pieter Oberholzer \\ Email: \\ oberp@mweb.co.za \\ Postal address: \\ Private Bag X24270, Gezina \\ 0031, South Africa \\ Dates: \\ Received: 04 Aug. 2014 \\ Accepted: 29 Oct. 2014 \\ Published: 05 Dec. 2014 \\ How to cite this article: \\ Oberholzer, PJ. Complete \\ rupture of the long head \\ of the biceps tendon and \\ the distal biceps tendon. $S$ \\ Afr J Rad. 2014;18(2); Art. \\ \#710, 3 pages. http://dx.doi/ \\ org/10.4102/sajr.v18i2.710
}

\section{Copyright:}

(C) 2014. The Authors.

Licensee: AOSIS OpenJournals. This work

is licensed under the Creative Commons

Attribution License.
Read online:
The most common injury to the biceps muscle is rupture of the long head of the biceps tendon. A tear can occur proximally, distally or at the musculotendinous junction. Two cases are discussed, in both of which the patients felt a sudden sharp pain in the upper arm, at the shoulder and elbow respectively, and presented with a biceps muscle bump (Popeye deformity).

\section{Introduction}

Patients with a biceps tendon rupture may complain of a wide variety of symptoms. Several report a sudden sharp pain in the anterior shoulder during activity, which may be accompanied by an audible 'pop' or a perceived snapping sensation. ${ }^{1}$ The patient may present with a Popeye deformity, where the disruption of the normal biceps muscle attachment leads to its retraction distally in the arm. A traumatic biceps tear is more common in younger patients but can occur at any age. It can occasionally occur during heavy weightlifting, from actions that cause a sudden load on the arm, local trauma, rapid extension of the arm or falling on an outstretched arm during competitive sports. The long head of the biceps tendon can also be injured by repetitive motion. ${ }^{2}$ Patients may still be able to use the biceps muscle, because of the intact short head of the biceps tendon which rarely tears. ${ }^{3}$ Proximal biceps tears do not always need surgical repair (depending on the patient's functionality), but distal tears need to be repaired.

\section{Case reports}

\section{Case 1}

A 38-year-old man presented with a Popeye deformity and a clinical diagnosis of ruptured long head of the biceps tendon. The injury occurred with the left arm in abduction and external rotation. A magnetic resonance image (MRI) was acquired to evaluate the biceps tendon.

An empty bicipital groove with an intact transverse ligament on the axial plane was diagnostic of a ruptured long head of the biceps tendon (Figure 1). The distal position of the retracted tendon was demonstrated in the sagittal plane (Figure 2). The biceps anchor was demonstrated in the coronal plane (Figure 3).

\section{Case 2}

A 28-year-old professional rugby player sustained an injury to his arm and was referred for MRI. A distal biceps tendon rupture with retraction was identified in the sagittal plane (Figure 4).

\section{Discussion}

Biceps tendon ruptures tend to occur at the following sites: ${ }^{4}$

- Proximal rupture at the superior aspect of the bicipital groove and rotator interval. This is the most common site and is usually part of the impingement spectrum.

- Distal rupture at the biceps anchor (radial tuberosity).

- Rupture at the musculotendinous junction is rare and is associated with violent trauma.

An absent long head of the biceps tendon in its expected location in the bicipital groove (on axial or sagittal images) is diagnostic ${ }^{4}$ of a proximal biceps tendon rupture. Some tears can be difficult to diagnose; for example, longitudinal and self-attaching tears. A longitudinal tear usually involves the superior part of the tendon, where a bifid tendon will extend inferior to the glenoid margin. ${ }^{4}$ A clinical diagnosis of a self-attaching long head of a biceps tendon rupture without retraction is challenging and is usually identified during a rotator cuff repair.

MRI is sensitive in diagnosing complete tears of the distal biceps tendon, but less sensitive for partial tears. ${ }^{5}$ The MRI features of a partial tear include intratendinous fluid signal, oedema in the 


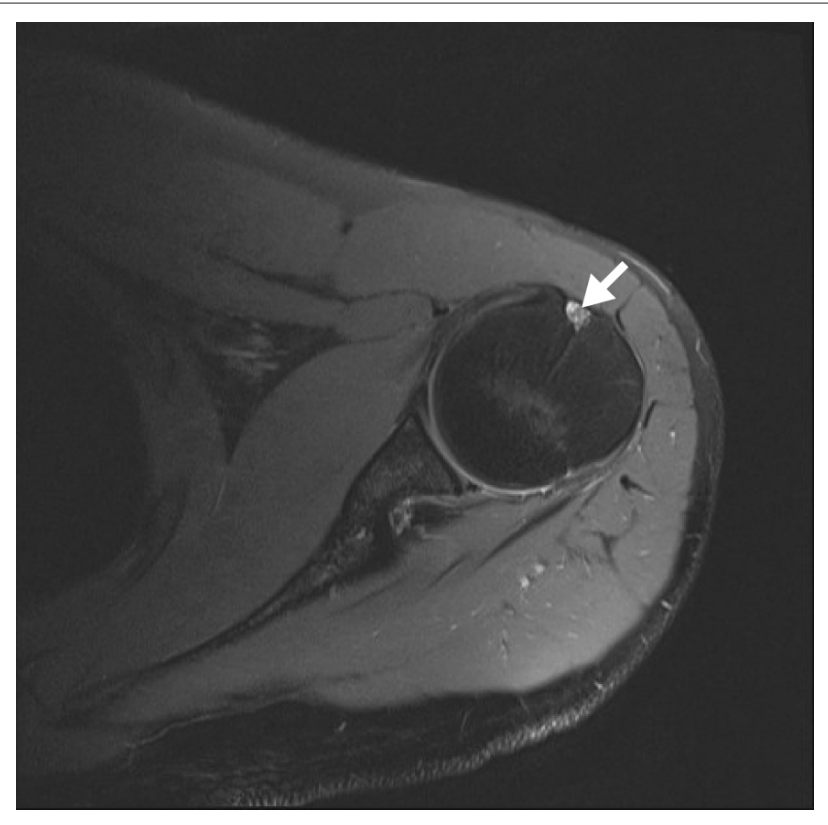

FIGURE 1: Magnetic resonance image (MRI) PD TSE FS in the axial plane, demonstrating an empty bicipital groove (arrow).

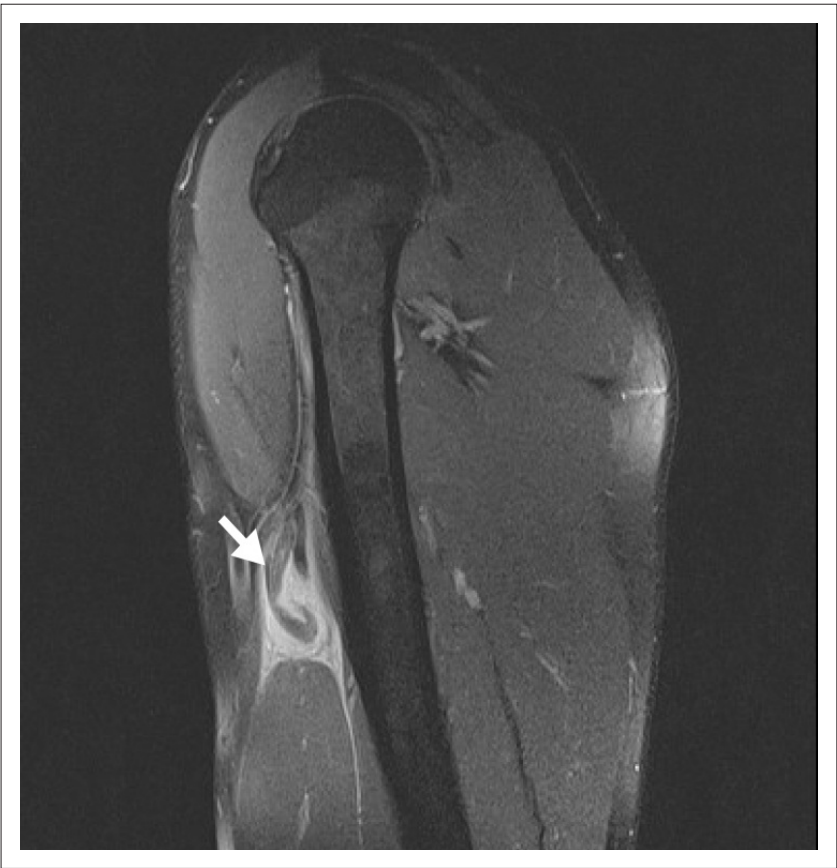

FIGURE 2: Magnetic resonance image (MRI) PD TSE FS in the sagittal plane, demonstrating the retracted tendon in the upper arm (arrow).

radial tuberosity and increased fluid signal intensity in the tendon sheath. Determining the degree of retraction in partial tears may provide a diagnostic challenge on MRI. Diagnosis should therefore not rely on imaging studies alone; correlation with history and clinical findings is necessary. ${ }^{2}$

The correct classification of a biceps tendon rupture is important because the management of proximal and distal biceps tendon tears differs. The biceps muscle is a flexor of the elbow and a supinator of the forearm. Repair of distal biceps tendon rupture is therefore generally always important. $^{2}$

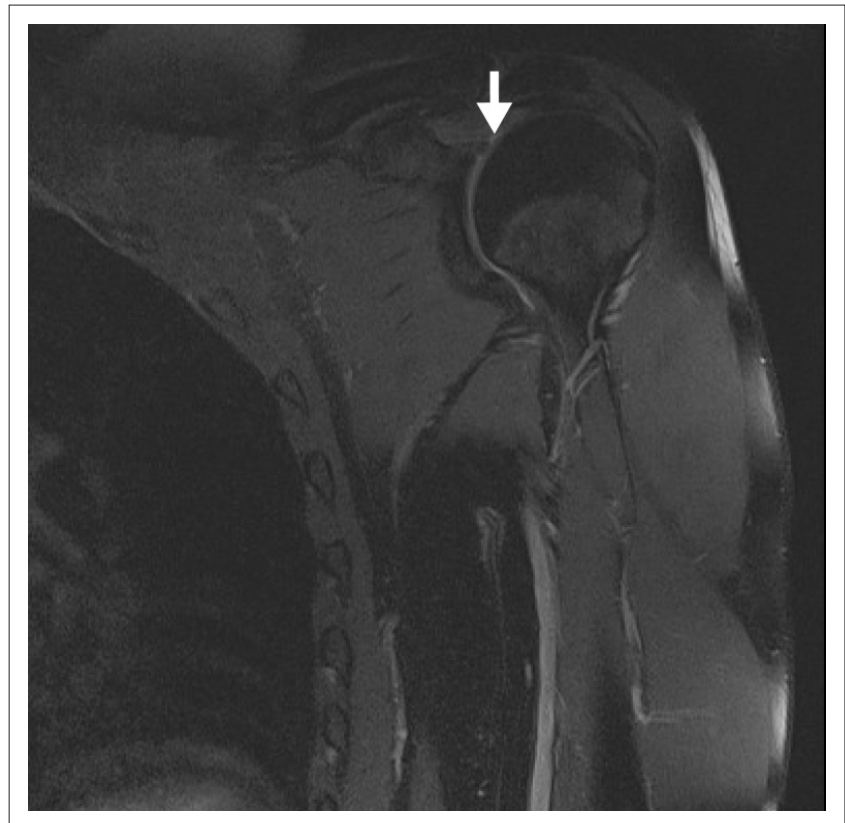

FIGURE 3: Magnetic resonance image (MRI) PD TSE FS in the coronal plane, demonstrating complete rupture of the biceps anchor (arrow).

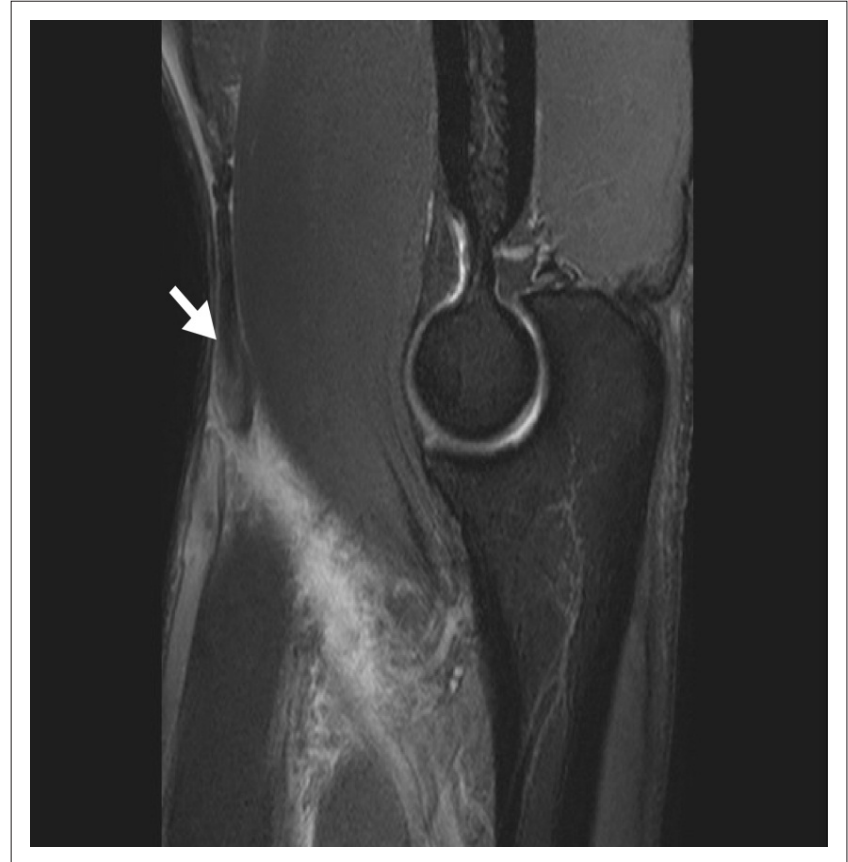

FIGURE 4: Magnetic resonance image (MRI) T2 FS in the sagittal plane, demonstrating complete tear of the distal biceps tendon (arrow).

The biceps tendon is also a weak flexor and passive stabiliser of the shoulder. Treatment of a proximal long head of the biceps tendon rupture consists of either a tenodesis, where the tendon is fixed in the bicipital groove, or a tenotomy (a release of the tendon). ${ }^{2}$ The latter often results in a permanent Popeye deformity.

\section{Teaching point}

In the event of a complete tear of the long head of biceps:

- identify the site of tear and the amount of retraction

- evaluate the proximal stump of the tendon. 
In the event of a complete tear of the distal biceps tendon (elbow):

- establish if the lacertus fibrosis is intact

- the field of view should be sufficient to identify the retracted stump.

\section{Conclusion}

A complete tear of the biceps tendon is usually a clinical diagnosis. MRI should be done to reveal the site, degree of tear, distance of retraction and trauma to surrounding soft tissue and bone.

\section{Acknowledgements}

I thank Drs S. Miller and M. Velleman, and M. Robbertse and D. Coetzee, for their contributions.

\section{Competing Interests}

The author declares that he has no financial or personal relationship(s) that may have inappropriately influenced him in writing this article.

\section{References}

1. Branch GL, Wieting JM. Biceps rupture. Medscape. Updated 28 February 2014 [homepage on the Internet]. [cited 21 May 2014]. Available from: http:// emedicine.medscape.com/article/327119-clinical

2. Reznik AM. The Orthopaedic Group. Biceps tendonitis, partial biceps tears, biceps subluxation, biceps rupture and biceps tenodesis. Revised 03 July 2011. togct.com/downloads/reznik

3. Ortholnfo. Biceps tendon tear at the shoulder. Updated May 2009. [homepage on the Internet]. [cited July 2014]. Rosemont: American Academy of Orthopedic on the Internet]. [cited July 2014]. Rosemont: American Academy of Orthop

4. Stoller DW. Magnetic resonance imaging in orthopaedics and sports medicine, vol. 2., 3rd edn. Philadelphia: Lippincott Williams \& Wilkens, 2007; p. 1423-1424.

5. Festa A, Mulieri PJ, Newman JS, Spitz DJ, Leslie BM. Effectiveness of MRI in detecting partial and complete distal biceps tendon ruptures. J Hand Surg Am. 2010;35(1):77-83. http://dx.doi.org/10.1016/j.jhsa.2009.08.016 